\section{O aumento no encarceramento e a redução nos homicídios em São Paulo, Brasil, entre 1996 e 2005}

\author{
Increased incarceration rate and reduction in \\ homicides in São Paulo, Brazil, from 1996 to 2005
}

Paulo Nadanovsky 1

\section{Introdução}

The social development of Brazilian States has generally not been followed by a reduction in homicide rates. A positive exception is the State of São Paulo, which experienced a clear reduction in its homicide rate from 1999 to 2005. There was a marked increase in the incarceration rate that preceded and then coincided with an equally important decline in the homicide rate. A bivariate Granger causality test showed that past incarceration rates helped predict homicide in the State of São Paulo from 1999 to 2005. Although it was not possible to conclude that this relationship is causal, a clear temporal association was observed, consistent with the interpretation that the increase in the incarceration of criminals had the effect of disabling or deterring crime in São Paulo. Other factors not assessed in this study may have caused the reduction in homicides in the State of São Paulo from 1999 to 2005.

Homicide; Prisons; Prisoners; Violence
Diante da grande melhoria nas condições sociais em todos estados do Brasil 1, ilustrada pelos avanços positivos na expectativa de vida ao nascer, que aumentou em média no Brasil de 58 anos em 1970 para 65 em 1991 e 72 em 2005, poder-se-ia esperar que melhorasse também a segurança. No entanto, parece que o desenvolvimento social do Brasil não tem sido acompanhado pela redução na violência. Entre os anos 2000 e 2005, somente dois estados brasileiros apresentaram uma clara redução na taxa de homicídio, Roraima e São Paulo (dados analisados, mas não apresentados). A redução da taxa de homicídio em São Paulo foi tão acentuada, num período tão curto de tempo e tão diferente do resto do país, que levanta a possibilidade de ter sido fruto de alguma política pública direcionada, específica daquele estado. A eficácia de tal política pode servir como exemplo para o resto do país. Portanto, é importante para o Brasil avaliar quais fatores estão associados a essa grande redução na taxa de homicídio em São Paulo. Um fator plausível, comprovadamente importante em outros países, é o encarceramento dos criminosos. O encarceramento de criminosos tem efeito incapacitador (com a prisão de criminosos eles são removidos das ruas e incapazes de cometer outros crimes enquanto encarcerados) e dissuador (o aumento na ameaça da punição induz os futuros criminosos a não cometer cri- 
mes que de outra forma eles ficariam tentados a cometer) ${ }^{2,3}$.

A hipótese geral deste pequeno estudo exploratório foi que à medida que aumentou a taxa de encarceramento, houve um subseqüente declínio na taxa de homicídio no Estado de São Paulo. A cobertura dos registros de óbitos em Roraima não foi tão completa quanto em São Paulo entre os anos 1990 e 2000 4. Além disso, foram encontrados dados disponíveis sobre a população prisional de Roraima somente a partir de 2003. Logo, este estudo incluiu apenas São Paulo.

Os objetivos deste estudo foram os seguintes: (1) descrever a redução na taxa de homicídio em São Paulo entre 1996 e 2005; (2) verificar se houve aumento na taxa de encarceramento em São Paulo entre 1996 e 2005; (3) verificar se o declínio na taxa de homicídio pode ter sido conseqüência do aumento na taxa de encarceramento.

\section{Método}

Foi realizado um estudo ecológico em que a unidade geográfica de observação foi o Estado de São Paulo. O período de observação foi de 1996 a 2005, com cada um desses dez anos representando uma unidade temporal de observação. A variável resposta foi a taxa de homicídio (10a revisão da Classificação Internacional de Doenças - CID10 5, códigos X85-Y09) - número de homicídios por cada 100 mil residentes. A variável explicativa foi a taxa de encarceramento, calculada pelo número de pessoas na prisão por cada $100 \mathrm{mil}$ residentes. Esse é o indicador padrão utilizado na literatura criminológica científica para avaliar o efeito incapacitador e dissuador do encarceramento no crime (e no homicídio especificamente), em estudos ecológicos 2,3.

Os dados foram obtidos da Secretaria de Administração Penitenciária de São Paulo (http://www.sap.sp.gov.br/common/dti/estatisticas/populacao.htm, acessado em Mai/2008) e do Ministério da Saúde do Brasil (http://www. datasus.gov.br).

Primeiramente foram examinados visualmente os gráficos da taxa anual de homicídio ao longo do tempo (1996 a 2005) e da taxa anual de encarceramento ao longo do tempo (1996 a 2005). Em seguida, foram confeccionados gráficos de dispersão da taxa anual de encarceramento ao longo do tempo (X) vs. taxa anual de homicídio ao longo do tempo (Y), testando os valores de $\mathrm{X}$ e $\mathrm{Y}$ defasados, i.e., $\mathrm{Y}(\mathrm{t}) v$ s. $\mathrm{X}(\mathrm{t}-1), \mathrm{Y}(\mathrm{t})$ vs. $\mathrm{X}(\mathrm{t}-2) \mathrm{e} \mathrm{Y}(\mathrm{t}) v$ s. $\mathrm{X}(\mathrm{t}-3)$, onde $\mathrm{t}=$ ano.

Se valores prévios de $\mathrm{X}$ ajudam a predizer $\mathrm{Y}$, mas valores prévios de $\mathrm{Y}$ não ajudam a predizer $\mathrm{X}$, podemos ter certeza de que a "causalidade" es- tá ocorrendo somente em uma direção ${ }^{3}$. Foram ajustadas, separadamente, regressões lineares da relação entre taxa anual de encarceramento (variável explicativa) e taxa anual de homicídio 1, 2 e 3 anos após (variáveis resposta); e da relação entre taxa anual de homicídio (nessa instância, variável explicativa) e taxa anual de encarceramento 1, 2 e 3 anos após (nessa instância, variáveis resposta).

Finalmente, foi realizado um teste de causalidade de Granger 3,6,7. Para testar formalmente a causalidade de Granger de encarceramento no homicídio, a seqüência de procedimentos adotada foi a seguinte: (1) foi realizada uma primeira regressão linear incluindo homicídio (variável resposta) e homicídio 3 anos antes (variável explicativa) para obter o residual sum of squares (RSS_r); (2) foi realizada uma segunda regressão linear incluindo homicídio (variável resposta), homicídio 3 anos antes e encarceramento 3 anos antes (variáveis explicativas) para obter o residual sum of squares (RSS_ur); (3) foi obtido o valor da estatística $F$, pela fórmula $F=$ [(RSS_r - RSS_ur) / $\mathrm{m}) /($ RSS_ur $/(\mathrm{n}-\mathrm{k})]$, onde $\mathrm{m}=$ número de termos defasados, $\mathrm{n}=$ número de casos e $\mathrm{k}=$ número de parâmetros na segunda regressão.

\section{Resultados}

A taxa de homicídio no Estado de São Paulo aumentou de 36 por 100 mil habitantes em 1996 para 44 em 1999. Desse momento em seguida a taxa reduziu até 21 em 2005. O número de pessoas na prisão por cada 100 mil habitantes aumentou constantemente de 182 em 1996 até 341 em 2005 (Figura 1).

Houve uma clara relação entre a taxa de encarceramento e as taxas de homicídio subseqüentes, 1, 2 ou 3 anos após. A taxa de encarceramento 3 anos antes previu melhor a taxa de homicídio do que as taxas de encarceramento 1 ou 2 anos antes (Figura 2).

Sessenta, 80 e 90 por cento da variação na taxa anual de homicídio foi explicada pela taxa anual de encarceramento 1, 2 e 3 anos antes, respectivamente. Por outro lado, a variação na taxa de encarceramento não pode ser explicada pela variação na taxa de homicídio, nem 1, 2 ou 3 anos antes (Tabela 1).

No teste de causalidade de Granger de encarceramento no homicídio, o RSS_r da primeira regressão (i.e., incluindo somente homicídio 3 anos antes como variável explicativa) foi 53.845 . O RSS_ur da segunda regressão (i.e., incluindo homicídio 3 anos antes e encarceramento 3 anos antes como variáveis explicativas) foi 25.778. O número de termos defasados (m) foi 1 (encarce- 
ramento 3 anos antes). O número de casos (n) foi 7 (encarceramento de 1996 a 2002 e homicídio de 1999 a 2005). O número de parâmetros na segunda regressão (k) foi 2 (homicídio 3 anos antes e encarceramento 3 anos antes). Aplicando a fórmula $F=$ [(RSS_r - RSS_ur) $/ \mathrm{m}) /($ RSS_ur $/(\mathrm{n}-\mathrm{k})]$, temos $[(53,845-25,778) / 1) /(25,778 /(7$ - 2)], então $F=5,44$. Valor de $F=5,44$ com 6 graus de liberdade, então $\mathrm{p}<0,05$. Portanto, os valores passados de encarceramento ajudaram a prever homicídio no Estado de São Paulo entre 1999 e 2005.

\section{Discussão}

A maior dificuldade para o estudo do efeito do encarceramento no crime, apontada na literatura de criminologia, é que a população prisional tende a aumentar e a diminuir em decorrência de aumentos e diminuições na quantidade de crimes. Nessa situação comum, muitas vezes fica difícil detectar um eventual efeito do encarceramento no crime, mesmo quando ele existe ${ }^{3}$. Ou seja, na situação usual, o pesquisador tem que tentar detectar mudanças na taxa de crime, subseqüentes e na direção contrária à taxa de encarceramento (muitas vezes embutidas numa aparente falta de associação quando os dados são examinados superficialmente), enquanto na situação de São Paulo a mudança da taxa de crime (indexada aqui pela taxa de homicídio) na direção contrária à taxa de encarceramento foi conspícua. Além disso, o teste de causalidade de Granger evidenciou que valores passados de encarceramento ajudaram a prever homicídio no Estado de São Paulo entre 1999 e 2005. Apesar de não ser possível concluir que essa relação seja causal, houve uma associação temporal clara compatível com a interpretação de que o aumento no encarceramento de criminosos exerceu seu efeito incapacitador e/ou dissuador do crime em São Paulo.

Nos Estados Unidos, as tendências foram muito similares às tendências identificadas no Estado de São Paulo (embora em números absolutos as taxas de homicídio em São Paulo sejam quase cinco vezes maiores). Naquele país, aconteceu um aumento na taxa de homicídio a partir dos anos 1960, atingindo um pico de 10 homicídios por cada 100 mil habitantes em 1980. Entre 1991 e 2000, a taxa de homicídio caiu de 10 para 5. A taxa de encarceramento começou a crescer em meados dos anos 1970 (como em São Paulo, antecedendo a redução no homicídio). Nos Estados Unidos, em 1970, a taxa de encarceramento era aproximadamente de 100 para cada 100 mil habitantes; em meados dos anos 1980 passou a 200 e em 1990 chegou a 300 2. Conseqüentemen-
Figura 1

Taxa de encarceramento e taxa de homicídio no Estado de São Paulo, Brasil, entre 1996 e 2005.

a) Taxa de encarceramento

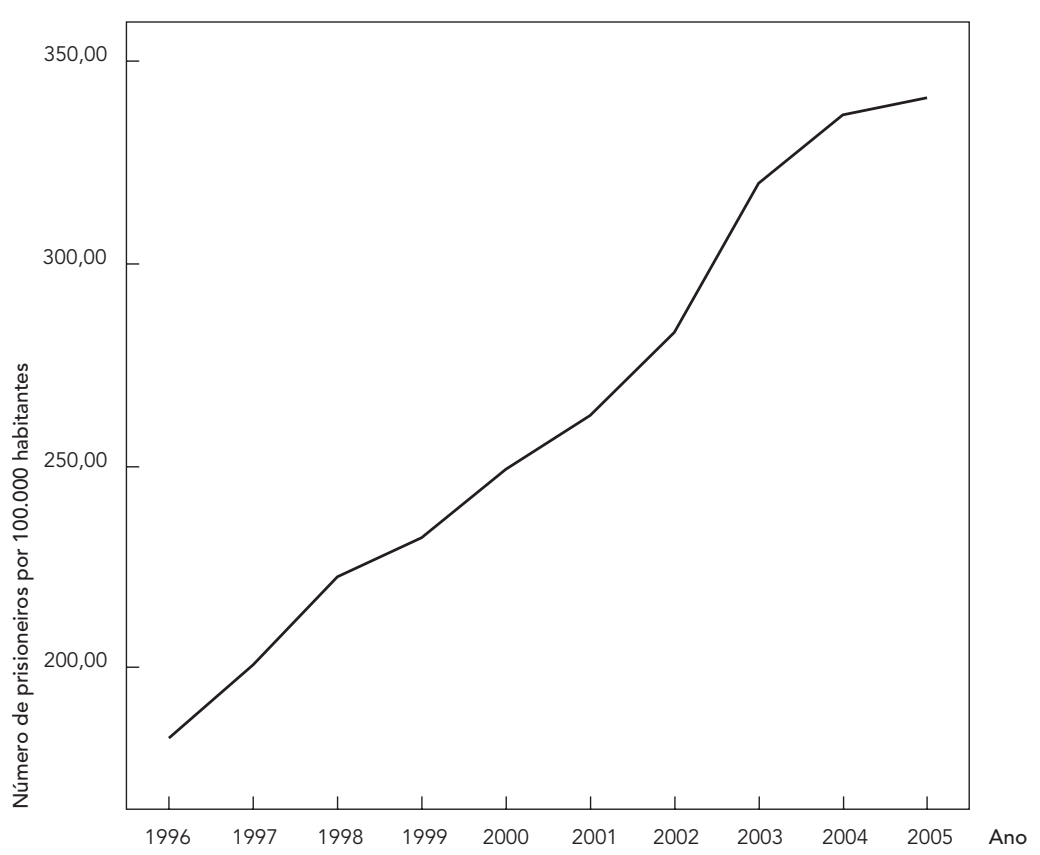

b) Taxa de homicídio

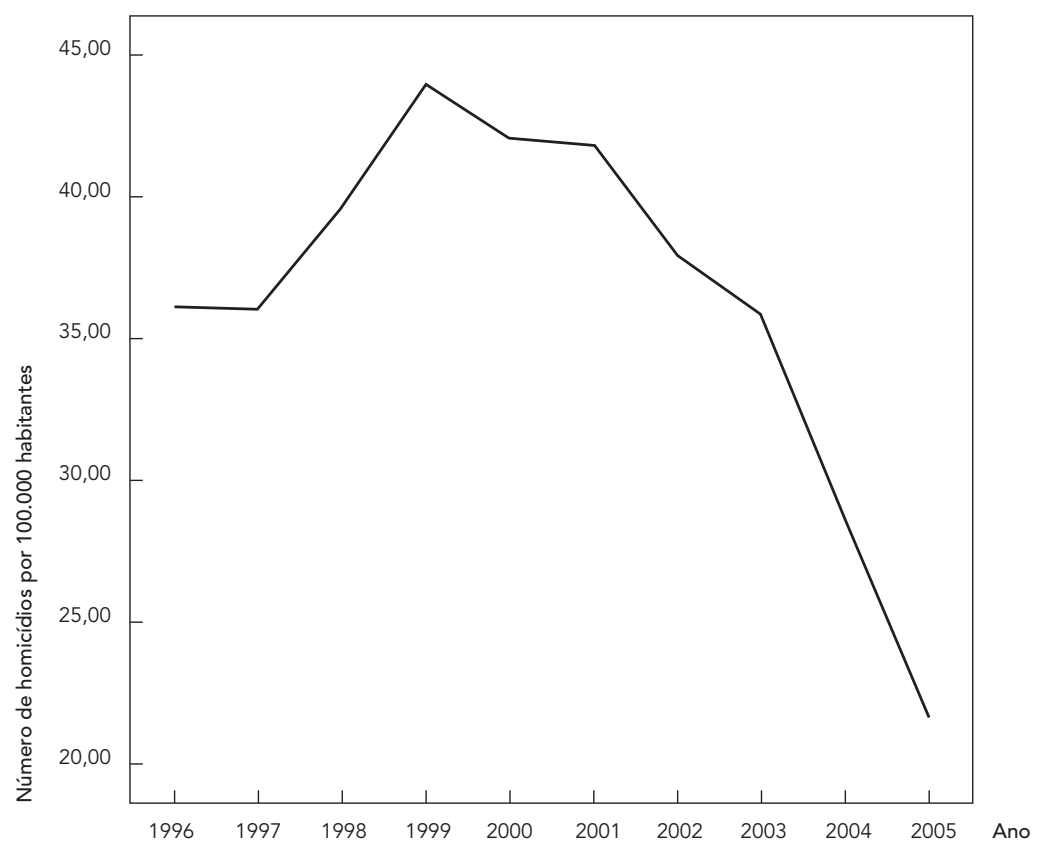


Figura 2

Relação entre taxa de encarceramento e taxa de homicídio 1, 2 e 3 anos após, no Estado de São Paulo, Brasil, entre 1996 e 2005.

a) Taxa de homicídio: lag de 1 ano

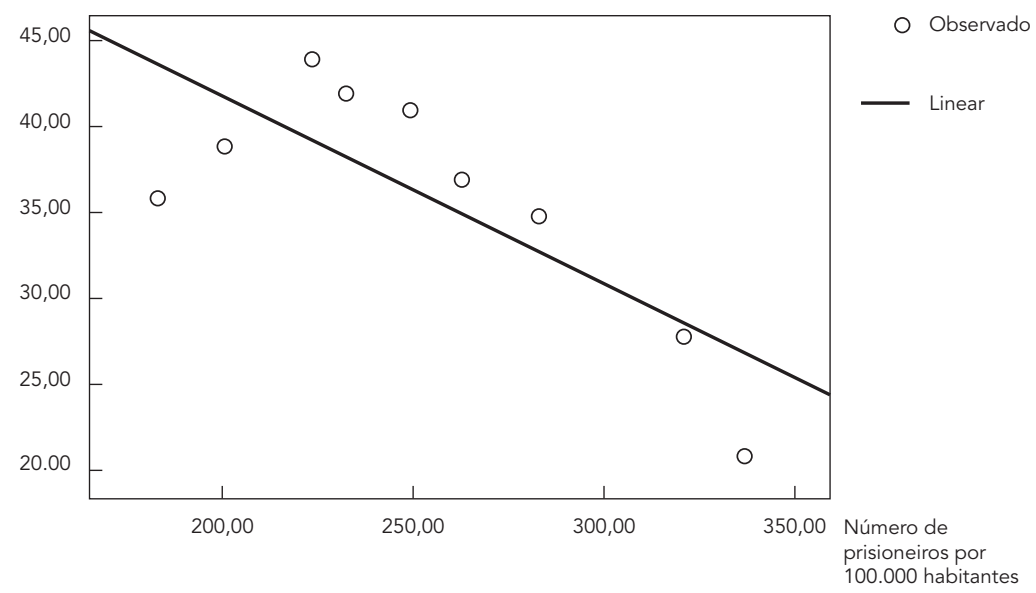

b) Taxa de homicídio: lag de 2 anos

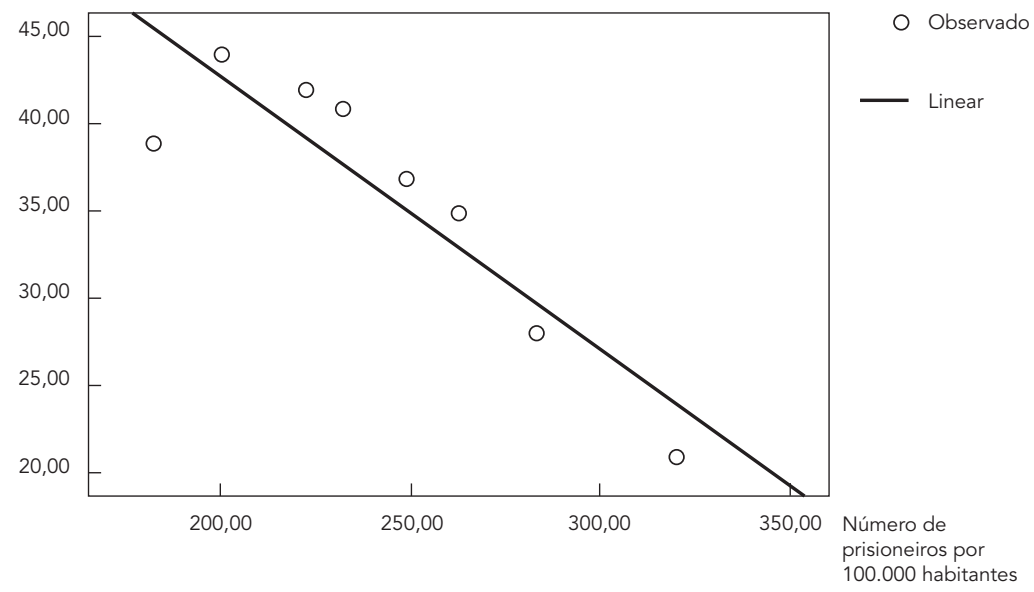

c) Taxa de homicídio: lag de 3 anos

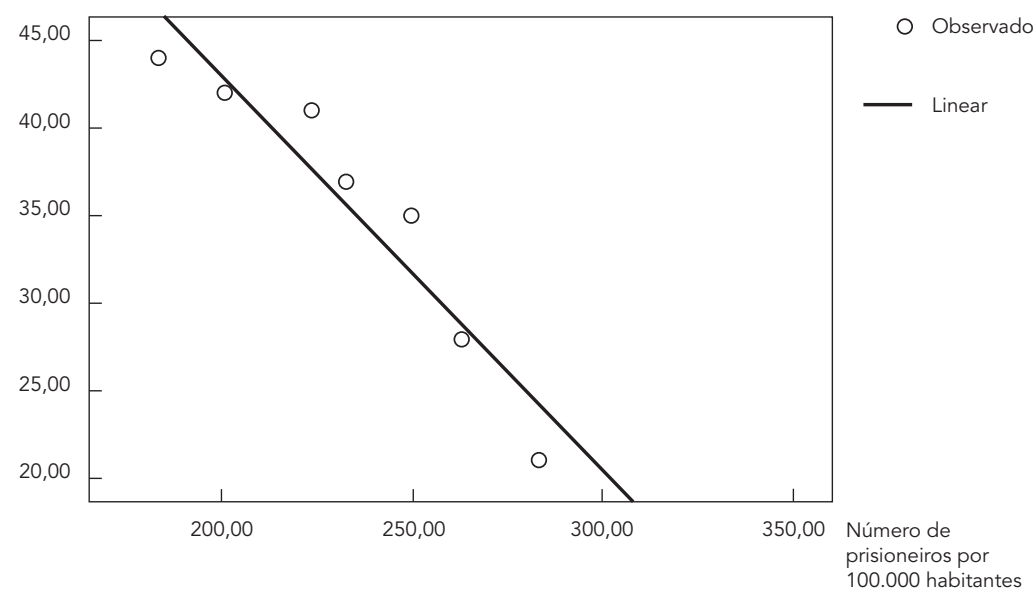

te, nos Estados Unidos, assim como no Estado de São Paulo, também ocorreu um aumento marcante na taxa de encarceramento (entre meados dos anos 1970 e meados dos anos 1980 - período em que a taxa de homicídio estava mais ou menos estacionada em 10 nos Estados Unidos), que antecedeu, e logo em seguida coincidiu, com um declínio igualmente expressivo na taxa de homicídio.

Inúmeros outros fatores não avaliados neste estudo podem ter causado a redução do homicídio no Estado de São Paulo entre 1999 e 2005. Com base em uma série temporal de taxa de homicídios e de encarceramento de apenas um estado brasileiro, as conclusões são mais tentativas do que assertivas. Por isso este estudo é uma “nota prévia”. Estudos futuros devem tentar montar um painel, i.e. taxas de homicídios e de encarceramento em vários estados brasileiros pelo mesmo período de tempo. Dessa forma seria mais fácil avaliar tendências gerais, investigar se há um efeito defasado do encarceramento na taxa de homicídios, ou se outras variáveis também poderiam explicar as tendências nas taxas de homicídio, incluindo desde políticas específicas de segurança pública a até mesmo a indesejável violência policial. Por exemplo, o excesso no uso de força pela polícia ao reagir ao crime, algo que a sociedade corretamente tenta combater, pode ter contribuído para a redução na taxa de homicídio em São Paulo ${ }^{8}$.

De qualquer forma, os dados avaliados neste estudo exploratório são consistentes com a hipótese de que o aumento no encarceramento de criminosos foi um fator importante para a redução na taxa de homicídio no Estado de São Paulo. No caso americano, existe consenso de que o aumento na taxa de encarceramento foi um fator importante para explicar o declínio na taxa de homicídio nos anos 1990 2,3. Outros fatores identificados, que contribuíram para a redução na taxa de homicídio naquele país, foram o aumento no número de policiais, a redução no mercado do crack (um tipo de droga ilegal que consiste na mistura de cocaína com bicarbonato de sódio) e a legalização do aborto. Fatores que foram avaliados, mas que tiveram um papel pequeno ou nenhuma influência na redução do homicídio nos anos 1990 nos Estados Unidos foram os seguintes: a economia forte do país nos anos 1990, mudanças demográficas, melhores estratégias de policiamento, leis de controle de armas de fogo, leis que permitem às pessoas andarem armadas e aumento no uso da pena de morte 2 .

Shepherd 9 chamou a atenção para a importância da dissuasão do crime como uma estratégia de saúde pública. A dissuasão do crime é um tema bem estabelecido na justiça criminal, no 
Regressões lineares da relação entre taxa anual de encarceramento (variável explicativa) e taxa anual de homicídio 1, 2 e 3 anos após (variáveis resposta); e da relação entre taxa anual de homicídio (nessa instância, variável explicativa) e taxa anual de encarceramento 1, 2 e 3 anos após (nessa instância, variáveis resposta), no Estado de São Paulo, Brasil, entre 1996 e 2005.

\begin{tabular}{|c|c|c|c|c|}
\hline Regressão linear & $\mathbf{R}^{2}$ & $F$ & Graus de liberdade & Significância \\
\hline \multicolumn{5}{|l|}{ Relação entre encarceramento e } \\
\hline Homicídio 1 ano após & 0,606 & 10,763 & 7 & 0,013 \\
\hline Homicídio 2 anos após & 0,806 & 24,984 & 6 & 0,002 \\
\hline Homicídio 3 anos após & 0,900 & 44,883 & 5 & 0,001 \\
\hline \multicolumn{5}{|l|}{ Relação entre homicídio e } \\
\hline Encarceramento 1 ano após & 0,163 & 1,360 & 7 & 0,282 \\
\hline Encarceramento 2 anos após & 0,004 & 0,026 & 6 & 0,877 \\
\hline Encarceramento 3 anos após & 0,247 & 1,644 & 5 & 0,256 \\
\hline
\end{tabular}

entanto seu papel na prevenção do assalto tem sido tratado com hostilidade na medicina 9. A violência no Brasil atingiu níveis tão alarmantes que a comunidade da saúde pública deveria jun- tar esforços com criminologistas e economistas e direcionar mais atenção às evidências importantes sobre fatores associados à redução da violência e do homicídio em outros países 2 .

\section{Resumo}

O desenvolvimento social dos estados do Brasil não tem sido acompanhado pela redução nas taxas de homicídio. O Estado de São Paulo é uma exceção positiva, porque nele houve uma clara redução na taxa de homicídio entre 1999 e 2005. Naquele estado houve um aumento marcante na taxa de encarceramento, que antecedeu, e logo em seguida coincidiu, com um declínio igualmente expressivo na taxa de homicídio. Um teste bivariado de causalidade de Granger revelou que valores passados de encarceramento ajudaram a prever homicídio no Estado de São Paulo entre 1999 e 2005. Apesar de não ser possível concluir que essa relação seja causal, constatou-se uma associação temporal clara, compatível com a interpretação de que o aumento no encarceramento de criminosos exerceu seu efeito incapacitador elou dissuador do crime em São Paulo. Outros fatores não avaliados neste estudo podem ter causado a redução do homicídio no Estado de São Paulo entre 1999 e 2005.

Homicídio; Prisões; Prisioneiros; Violência

\section{Agradecimentos}

Ao Antônio Ponce de Leon e ao Roger Keller Celeste, por comentários e sugestões após leitura de uma versão inicial desse artigo. Todas as análises estatísticas e demais metodologias são inteiramente de minha responsabilidade. Ao Conselho Nacional de Desenvolvimento Científico e Tecnológico (CNPq) pela bolsa de produtividade em pesquisa e pela bolsa de pós-doutorado, período em que o presente estudo foi realizado. 


\section{Referências}

1. Albuquerque RC. Um balanço social do Brasil, 1980-2005. Rio de Janeiro: Instituto Nacional de Altos Estudos; 2007. (Estudos e Pesquisas, 206).

2. Levitt SD. Understanding why crime fell in the 1990s: four factors that explain the decline and six that do not. J Econ Perspect 2004; 18:163-90.

3. Spelman W. What recent studies do (and don't) tell us about imprisonment and crime. Crime and Justice 2000; 27:419-94.

4. Paes NA. Avaliação da cobertura dos registros de óbitos dos estados brasileiros em 2000. Rev Saúde Pública 2005; 39:882-90.

5. Organização Mundial da Saúde. Classificação estatística internacional de doenças e problemas relacionados à saúde, 10a revisão. São Paulo: Centro Colaborador da OMS para a Classificação de Doenças em Português; 1995.
6. Granger CWJ. Investigating causal relations by econometric models and cross-spectral methods. Econometrica 1969; 37:424-38.

7. Granger CWJ. Testing for causality: a personal viewpoint. J Econ Dyn Control 1980; 2:329-52.

8. Clark TW. Structural predictors of Brazilian police violence. Deviant Behav 2008; 29:85-110.

9. Shepherd JP. Criminal deterrence as a public health strategy. Lancet 2001; 358:1717-22.

Recebido em 25/Ago/2008

Versão final reapresentada em 30/Abr/2009

Aprovado em 13/Mai/2009 